\title{
Review of Research Trends in Learning and the Internet in Higher Education
}

\author{
Adrián Segura-Robles ${ }^{1}{ }^{(\mathbb{C}}$, Antonio-José Moreno-Guerrero ${ }^{2, *} \mathbb{C}$, María-Elena Parra-González ${ }^{1}(\mathbb{D})$ \\ and Jesús López-Belmonte ${ }^{2} \mathbb{D}$ \\ 1 Department of Research Methods and Diagnosis in Education, University of Granada, 51001 Ceuta, Spain; \\ adrianseg@ugr.es (A.S.-R.); elenaparra@ugr.es (M.-E.P.-G.) \\ 2 Department of Didactics and School Organization, University of Granada, 51001 Ceuta, Spain; \\ jesuslopez@ugr.es \\ * Correspondence: ajmoreno@ugr.es
}

Received: 26 April 2020; Accepted: 9 June 2020; Published: 12 June 2020

\begin{abstract}
Within the scientific literature, there has been much debate about the use of the Internet in teaching in university contexts. The potential of this tool and its educational possibilities is well documented. The main purpose of this study is to analyze the use of the Internet in university teaching from a bibliometric perspective. To analyze scientific works, scientific mapping strategies have been used; for example, exploring the co-words and co-authors in works on this topic. We have worked with an analysis unit of 5118 documents which are indexed in the Web of Science database. Among the findings of this research, it can be highlighted that most publications are in English-the topic has been thoroughly studied and works have been published in this language over time. Moreover, the United States is the country which is most productive in relation to educational and computing fields. The most relevant topics themes are "e-learning", "systems" and "Internet of Things".
\end{abstract}

Keywords: internet; higher education; learning; bibliometric analysis; scientific mapping

\section{Introduction}

The Internet has not only revolutionized the way we relate to each other, but it has also changed the way we communicate (Danet and Herring 2007). A large number of scientific studies show how people use mobile phones and the Internet for their own leisure rather than for educational or work reasons. The Internet has shown its effectiveness in most of the studies in which it has been tested; in particular, the potential of WhatsApp has been made clear (Koparal et al. 2019; Rathbone et al. 2020; Segura-Robles et al. 2019). The study and analysis of the evolution of different topics in the scientific literature is an important aspect of scientific knowledge. This information foreshadows the research potential of a particular field (Allen et al. 2009; Khiste and Paithankar 2017). The main purpose of this study lies in the need to lay the foundations for the scientific development of Internet applications in higher education since there are no precedents for similar research.

The weight that the use of the Internet has in all areas of our lives, including education, is obvious. Although this transformation has occurred rapidly in the educational system, the Internet has transformed the university system in a significant way. Studies such as those of Baer (1998) and Taylor (1995) already predicted the potential usefulness of the Internet and how it would transform the entire university system.

The use of the Internet as a tool for university teaching has proven to be very effective. One of the types of university education which has benefited most from this change is distance education (Beyth-Marom et al. 2003) or blended learning (Djenic et al. 2011; Sun 2016). We must not make the mistake of believing that all aspects are positive; the use of connected technology or tools can present 
distraction problems among students (Chen et al. 2020; Feng et al. 2019; Rana et al. 2019), privacy issues (Gogus and Saygın 2019; Kurt 2010), and frustration due to errors on platforms (Borko et al. 2008; Golonka et al. 2012) or slow connections (Rossing et al. 2012).

From a more current perspective, we cannot ignore the role of the Internet, especially in the development of social platforms (social media) and how they have transformed the way in which we relate to each other today (Datu et al. 2018; Moorthy et al. 2019). The introduction of these types of tools in class should not focus on how many "likes" or "views" can be obtained when uploading a video on YouTube, but should be seen as an open environment with great possibilities to develop creativity and critical thinking (González-Hernando et al. 2020).

In the current scientific literature, there is no analysis of the literature on the introduction and evolution of the Internet in higher education. Most of the available studies are old (Kaminer and Braunstein 1998) or focus on very specific topics that prevent a good understanding of the evolution of this tool in university teaching, such as the use of smartphones (Carbonell et al. 2009), the use of remote virtual laboratories (Heradio et al. 2016) or aspects of Internet security (Sakhnini et al. 2019).

Due to the positive aspects detected in the previous literature and the lack of similar and current research, the study focuses on the analysis of works on the use of the Internet as a learning tool in the university context $\left(\mathrm{LINU}^{1}\right)$.

\section{Justification and Objectives}

In this research, the terms "learn" (and its morpheme derivatives), "Internet" and "higher education" (and its synonym "university") have been taken as analytical constructs in the scientific works indexed in the Web of Science (WoS) database. After conducting a search process for studies that have analyzed the concepts "learn", "Internet", "higher education" and "university" and from a bibliometric perspective in the aforementioned database, no publication on the state of the question was found that uses documentary analytical techniques such as scientific mapping. This leads the present investigation to acquire an exploratory perspective, contributing to reducing the gap caused by the absence of scientific publications on this topic. Furthermore, the results and conclusions presented in this work will serve as the basis and starting point for future research, achieving an advance in science. Likewise, this will foster the interest of different members of the scientific community in this field of knowledge.

Therefore, this study aims to analyze the overall projects dealing with such terms in the specialized WoS literature. Along these lines, the objectives formulated to guide the conduct of the research are as follows:

- To determine the number of the scientific publications with the concepts "learn", "Internet" and "higher education" in WoS.

- To determine the scientific evolution of "learn", "Internet" and "higher education" in WoS.

- To specify the most prominent topics for "learn", "Internet" and "higher education" in WoS.

- To determine the most productive and influential authors regarding "learn", "Internet" and "higher education" in WoS.

\section{Materials and Method}

\subsection{Research Design}

To enable the objectives to be achieved, a bibliometric methodology was used in this research, based on the potential of scientometry to search, report, record, analyze and predict scientific works (Martínez et al. 2015; Parra-González and Segura-Robles 2019). Within this research, the guidelines and

1 LINU. This is the abbreviation established by the researchers of this study to describe the use of the Internet in university student learning. 
premises of experts in this type of study have been followed to develop an effective research method (Moral-Muñoz et al. 2020).

Various analytical techniques have been used, such as scientific mapping, the quantification of different bibliometric indicators (year of publication, language, publication area, type of documents, organizations, authors, sources of origin, countries and citation) and the structural and dynamic development of the terms presented. Specifically, this study has been based on an analysis of co-words and authors (Hirsch 2005), applying certain academic indices to establish academic performance ( $h, g$, hg, q2) (Cobo et al. 2011). The h-index is an indicator used to measure the quality of the production of scientists according to the number of citations received in their publications. The g-index allows us to delve into the productive analytics of researchers who have a similar value in the h-index. The hg-index is a combination of the previous indexes. It allows us to obtain a result that takes into account the potentialities of the " $\mathrm{h}$ " and " $\mathrm{g}$ " indexes and reduces their drawbacks. Finally, the q2-index is made from a quantitative measure (h-index) and another based on qualitative properties of the $\mathrm{h}$-core (Alonso et al. 2010; Cabrerizo et al. 2010).

This method is followed in order to generate maps with nodes that will establish both the position and the performance of the subdomains of the analyzed constructs. Likewise, these actions will allow the determination of the thematic development of the established terms (López-Robles et al. 2019).

For an effective analytical structure and presentation of results, previous studies that have used this type of research design have been followed, which have been reported from the impact literature indexed in the Journal Citation Reports (JCR), revealing an analysis model which has been validated by experts (López et al. 2019; López et al. 2020; Rodríguez-García et al. 2019).

\subsection{Procedure and Data Analysis}

To carry out this investigation, different procedures were carried out: (a) selection of the database; (b) establishment of the keywords to analyze; (c) preparation of the search equation (("learn*") AND ("Internet") AND ("higher education" OR "university")); (d) entering the equation in the WoS search field under the TITLE tag to specify the documentary report in the title, abstract and keywords of the existing production.

Following this method, we found an initial amount of 5187 scientific papers in an open search of the WoS database. The first result was found in 1993. This led to the establishment of a study range from 1993 to 2019. Publications concerning the year 2020 have not been taken into consideration as the year had not ended, and its inclusion could lead to a bias in the investigation. A total of 39 documents have been deleted due to duplication or indexing errors. Finally, we worked with an analysis unit of 5118 documents.

All these actions have been carried out following the protocols of the PRISMA-P matrix for reviews of the scientific literature. This has led to the creation of a flow diagram (Figure 1).

Various tools have been used to approach the analysis of works, such as Analyse Results, Creation Citation Report and SciMAT. The first two are offered by WoS on its platform and allow the extraction and analysis of allusive data per year, authorship, country, type of document, institution, language, medium and most cited documents. SciMAT is a software tool that analyzes scientific works, taking the words longitudinally and taking into account their structural and dynamic development. The guidance of experts in the use of this tool has been followed to carry out an accurate and effective analysis (Montero-Díaz et al. 2018). With SciMAT, recognition, reproduction, determination and performance processes have been carried out, which are detailed below:

- Recognition: In this process, the keywords of the publications obtained were analyzed $(n=11,139)$. Both a co-occurrence node map and a standardized network of co-words were made. To do this, a keyword debugging was performed, finally analyzing 10,443 keywords. Finally, the most incidental themes and concepts were established with a clustering algorithm.

- Reproduction: In this process, a strategic diagram and a thematic network were created based on the principles of centrality and density. Four areas were specified in the figures with their 
particularities: motor and important issues (upper right area), isolated and entrenched issues (upper left area), issues that are projected or are disappearing (lower left area) and issues with a low and transversal level of development (lower right area).

- Determination: In this process, the elaborated nodes corresponding to the different predetermined periods or time intervals were analyzed. For the study of co-words, five periods were configured, taking as a criterion the scope of 1000 documents per period (P1 = 1993-2005; P2 = 2006-2010; P3 = 2011-2013; P4 = 2014-2016; P5 = 2017-2019). For the authors' analysis, a single period covering the entire work has been established (PX =1993-2019). The number of keywords in common between the periods produced the strength of association. The interval diagrams show data on the importance of each of the themes in the established periods, following a process of grouping, taking as a reference the Callon indicators, which study the degree of interaction of a network with respect to other networks, from two perspectives: centrality, which analyzes the strength of external links with other topics, as the measure of the importance of a topic in the development of a certain field of research; and density, which studies the internal strength of the network, analyzing the internal links between all the keywords that are grouped around a specific topic, thus showing the degree of development of the field of study analyzed.

- Performance: In this process, production indicators were established with their relative inclusion criteria to analyze the reported scientific literature. Bearing in mind the indicators listed in Table 1, it can be observed that the unit of analysis focuses on the unit of evaluation itself; in this case, the keywords of the manuscripts. The frequency threshold marks the minimum frequency of intervals, i.e., the minimum required number of keywords or topics that coincide with each other. The type of network generates a multiple connection of co-occurrence of words and authors. The linkage value generates the number of coincidences between thematic networks. The normalization of connections is based on the equivalence index eij = cij2/Root (ci - cj). The clustering algorithm, by means of simple centers, makes the map of subjects and related subnetworks. The evolutionary measure, through the Jaccard Index, shows the similarity measure that elaborates the evolutionary map and the transition map through the inclusion rate.

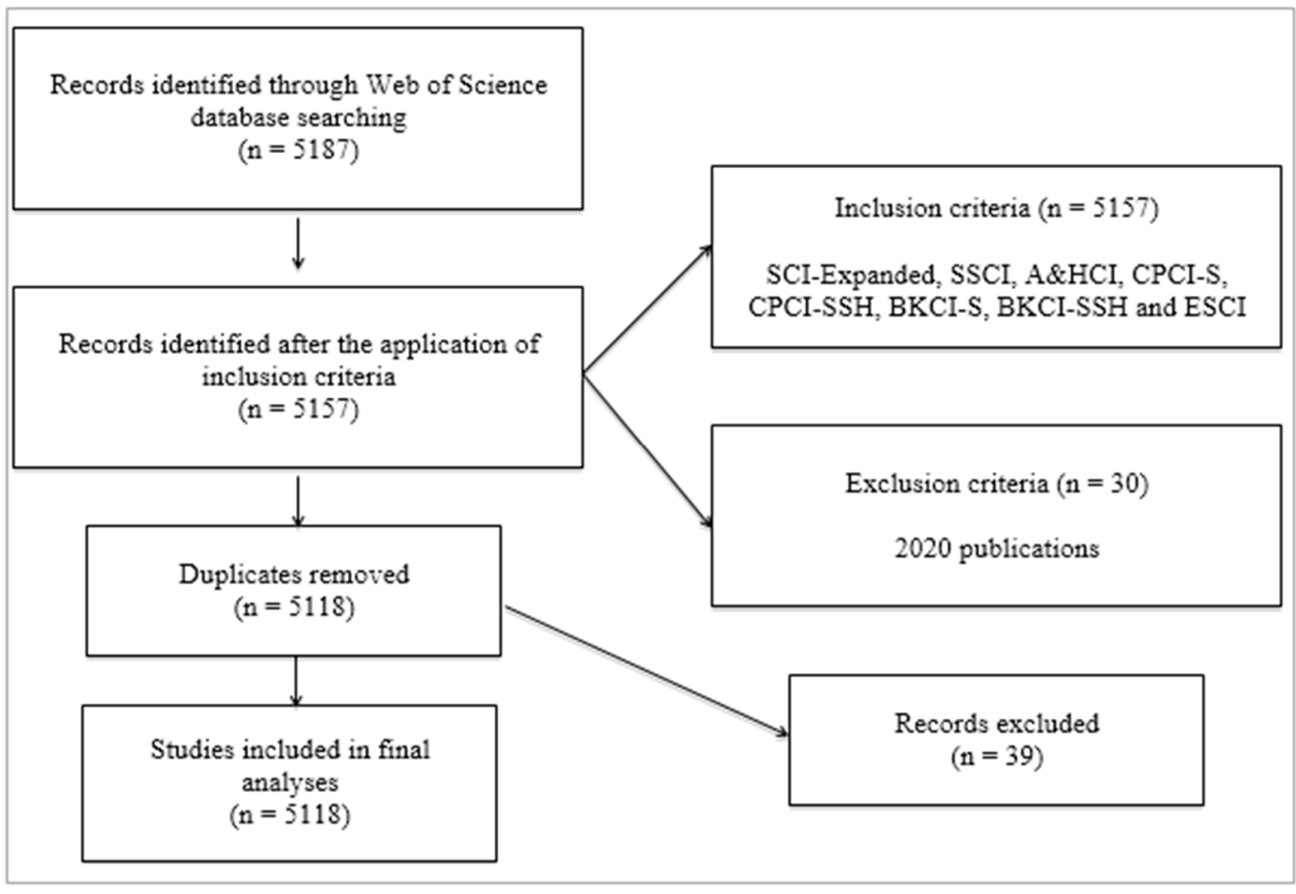

Figure 1. Flowchart according to the PRISMA Declaration. 
Table 1. Production indicators and inclusion criteria.

\begin{tabular}{cc}
\hline Configuration & Values \\
\hline Analysis unit & Keywords authors, keywords $\mathrm{WoS}$ \\
Frequency threshold & Keywords: $\mathrm{P}_{1}=(2), \mathrm{P}_{2}=(5), \mathrm{P}_{3}=(5), \mathrm{P}_{4}=(5), \mathrm{P}_{5}=(5)$ \\
Network type & Authors: $\mathrm{P}_{\mathrm{X}}=(3)$ \\
Co-occurrence \\
Co-occurrence union value threshold & Keywords: $\mathrm{P}_{1}=(2), \mathrm{P}_{2}=(3), \mathrm{P}_{3}=(3), \mathrm{P}_{4}=(3), \mathrm{P}_{5}=(3)$ \\
Normalization measure & Authors: $\mathrm{P}_{\mathrm{X}}=(2)$ \\
Clustering algorithm & Equivalence index \\
Evolutionary measure & Maximum size: ; Minimum size: 3 \\
Overlapping measure & Jaccard index \\
& Inclusion Rate \\
\hline
\end{tabular}

\section{Results}

\subsection{Scientific Performance and Production}

The number of reported documents from the scientific literature amounts to a total of 5118 publications. The works began in 1993, following a pattern of irregular production to date. From 1993 to 1998, the production is ascending and constant, although with a small amount of production. Between 1999 and 2000, there is a decrease in production, rebounding from 2001 to 2005. In this period, the production follows the same pattern as from 1993 to 1998, but with a difference in the amount of production, which is much higher. In 2006, there is a further decline, although from 2007 to 2012, the growth curve is high, with a constant and voluminous production. In 2013 and 2014, there is a further decline, with a rebound in 2015 to 2017. In 2018 and 2019, production falls sharply, bringing the volume of production back to 2010 levels (Figure 2).

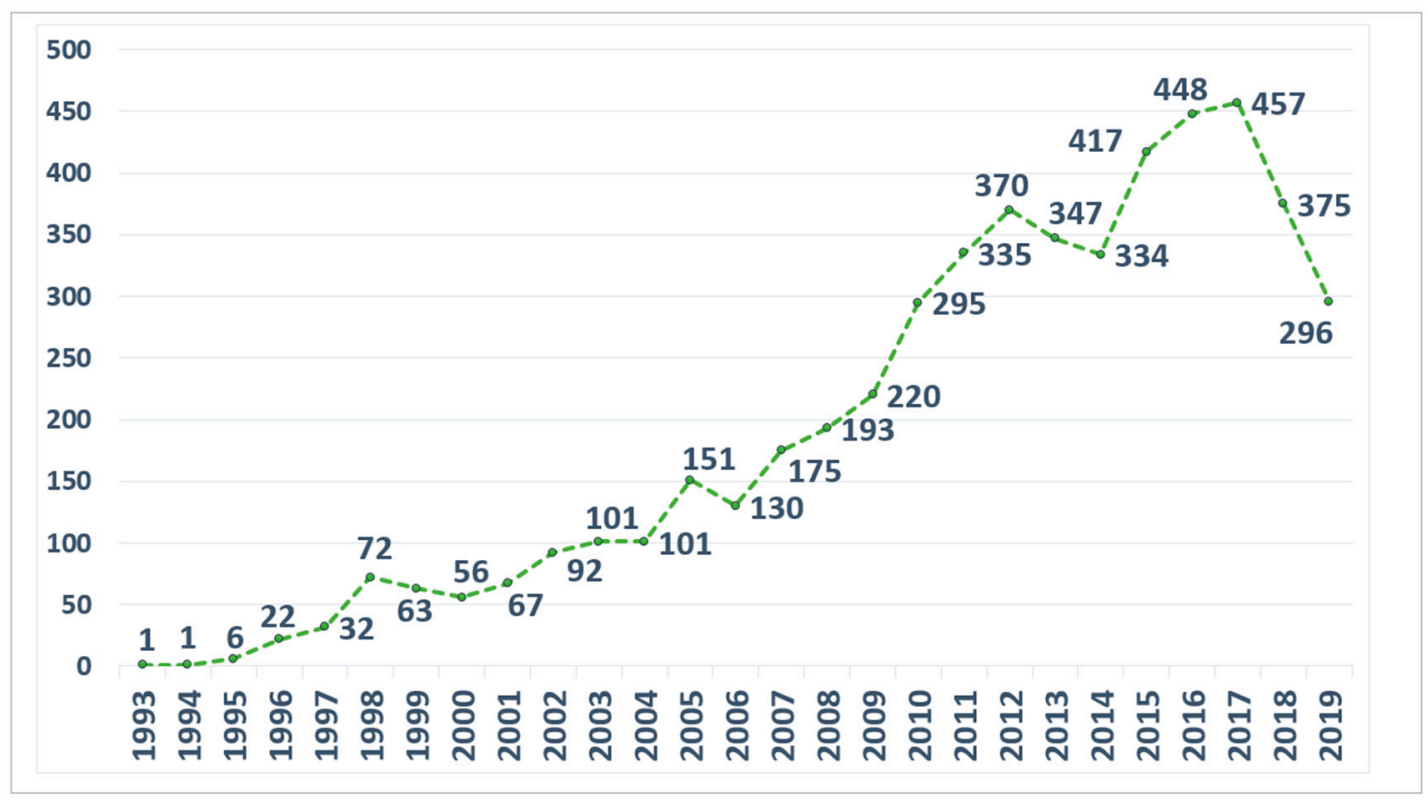

Figure 2. Evolution of scientific works regarding the Internet as a learning tool in the university context (LINU).

The language used mainly by the scientific community for the elaboration of the documents is English $(n=4752)$, followed by Spanish $(n=220)$. The remaining languages do not exceed 50 works in total. The area of knowledge that LINU occupies in WoS focuses mainly on the category education and educational research $(n=2952)$, followed by computer science $(n=1200)$ and engineering $(n=659)$. The remaining areas do not exceed 300 works in total. The document types published in the scientific 
community to present research are articles $(n=2630)$ and conference papers $(n=2526)$. The other documents do not exceed 120 works in total. The institutions with the highest numbers of works are the State University System of Florida $(n=44)$ and the University of Seville $(n=38)$. The other institutions have a production of under 31 documents. The authors with the highest numbers of scientific works are Tsai, C.C. $(n=20)$, who has published much more than Machotka, J. $(n=13)$ and Nedic, Z. $(n=13)$. The remaining authors have production levels of fewer than 11 publications. The source of production is mainly focused on conference papers, as shown by the works of EDULEARN Proceedings $(n=257)$ and INTED Proceedings $(n=180)$; the rest of the documents related to conference papers number fewer than 80 documents. The main journals are Procedia Social and Behavioral Science $(n=108)$, followed by Computers and Education $(n=73)$. The rest of the documents number below 67 . The country with the highest scientific production in this area is the United States $(n=883)$, followed by Spain $(n=534)$. The rest of the countries have produced fewer than 360 works. The most frequently cited publications in the field of LINU are those of Kietzmann et al. (2011), with 1232 citations; Mangold and Faulds (2009), with 1033 citations; and Cook et al. (2008). The remaining references exhibit below 600 citations.

\subsection{Structural and Thematic Development}

The evolution of keywords shows data on those keywords (World-Wide-Web, Internet, Intention, Facebook and Technology, among other topics) that are omitted, those that are used and those that coincide between certain periods. In this case, it is observed that between P1 and P2, and between P3 and $\mathrm{P} 4$, there is a coincidence of more than $30 \%$, which shows that between these periods, the study basis has been coincidental and has been based on a general line of research. On the other hand, the number of matching keywords between the second and third period, and between the fourth and fifth period, is less than 30\%; in other words, the number of matching words between these periods is $27 \%$ and $28 \%$, respectively. That is, it shows discrepancies in the lines of investigation, either because new lines of research are being offered, or because there are several lines of research being carried out at the same time (Figure 3).

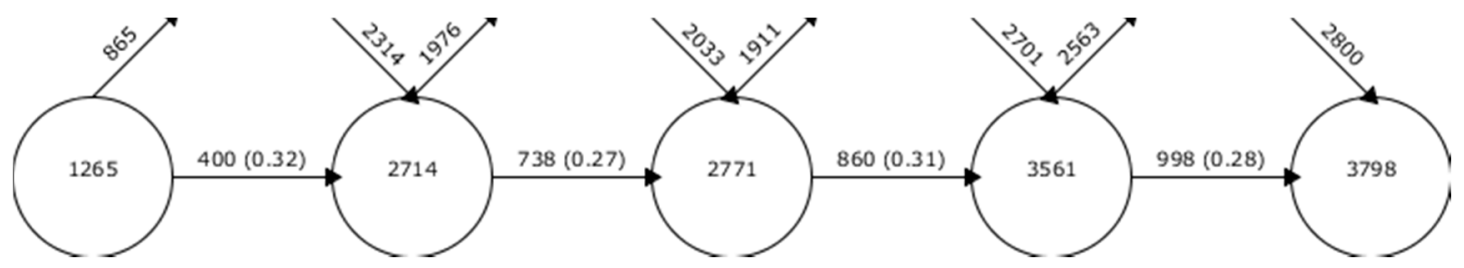

Figure 3. Continuity of keywords between contiguous intervals.

The academic performance of the established time intervals offers, by means of bibliometric indicators (h-index, g-index, hg-index, q2-index), the most relevant and important topics in the study of LINU. In this case, it can be seen that, in the first period, the subject matter with the highest h-index is "World-Wide-Web", which is considerably different from the topic with the next-highest h-index, "students". In the second and third periods, the subject matter with the highest h-index is "Internet". In addition, in both periods, other subjects, such as "higher education", are shown to be relevant; however, in both cases, these are far from the significance of "student". In the fourth period, the bibliometric levels are even, with new themes appearing, such as "intention", "Facebook" and "attitudes". In the fifth period, the theme with the highest h-index is "technology", although there are other relevant but distant themes, such as "university students", "self-efficacy" and "usage". In all periods, variances in the themes can be observed (Table 2). 
Table 2. Thematic performance in LINU.

\begin{tabular}{|c|c|c|c|c|c|c|}
\hline \multicolumn{7}{|c|}{ Interval 1993-2005 } \\
\hline Title & Works & H Index & G Index & HG Index & $\mathrm{Q}^{2}$ Index & Quotes \\
\hline Atrial-Cell & 5 & 1 & 1 & 1 & 1.41 & 5 \\
\hline World-Wide-Web & 26 & 11 & 22 & 15.56 & 16.25 & 510 \\
\hline Distance-Learning & 14 & 4 & 5 & 4.47 & 6 & 30 \\
\hline E-learning & 10 & 2 & 5 & 3.16 & 13.11 & 93 \\
\hline Education & 17 & 6 & 14 & 9.17 & 11.49 & 197 \\
\hline Distance-education & 13 & 4 & 7 & 5.29 & 6.32 & 53 \\
\hline Students & 12 & 7 & 12 & 9.17 & 16.73 & 260 \\
\hline Model & 5 & 5 & 5 & 5 & 19.62 & 768 \\
\hline Higher-Education & 6 & 4 & 4 & 4 & 6.63 & 41 \\
\hline $\begin{array}{l}\text { Computer-Mediated- } \\
\text { Communication }\end{array}$ & 3 & 3 & 3 & 3 & 8.66 & 81 \\
\hline \multicolumn{7}{|c|}{ Interval 2006-2010 } \\
\hline Title & Works & H Index & G Index & Hg Index & $\mathrm{Q}^{2}$ Index & Quotes \\
\hline Internet & 88 & 22 & 40 & 22.66 & 30.03 & 1818 \\
\hline Students & 21 & 12 & 18 & 14.7 & 21.91 & 666 \\
\hline Higher-Education & 55 & 13 & 29 & 19.42 & 18.73 & 889 \\
\hline University-Students & 15 & 9 & 13 & 10.82 & 21.63 & 613 \\
\hline Information-Technology & 9 & 8 & 8 & 8 & 19.6 & 507 \\
\hline Medical-education & 9 & 6 & 8 & 6.93 & 11.49 & 189 \\
\hline Innovation & 4 & 3 & 4 & 3.46 & 7.14 & 50 \\
\hline Internet-use & 5 & 2 & 3 & 2.45 & 14.21 & 128 \\
\hline Distance-learning & 7 & 1 & 2 & 1.41 & 4 & 17 \\
\hline \multicolumn{7}{|c|}{ Interval 2011-2013 } \\
\hline Title & Works & H Index & G Index & Hg Index & $\mathrm{Q}^{2}$ Index & Quotes \\
\hline University-Students & 20 & 9 & 15 & 11.62 & 13.42 & 327 \\
\hline Online & 23 & 12 & 20 & 15.49 & 15.49 & 472 \\
\hline Internet & 99 & 17 & 27 & 21.42 & 19.77 & 915 \\
\hline E-learning & 32 & 5 & 11 & 7.42 & 6.32 & 143 \\
\hline Web 2.0 & 19 & 4 & 11 & 6.63 & 17.89 & 1408 \\
\hline Perceptions & 13 & 6 & 11 & 8.12 & 10.95 & 157 \\
\hline Teaching/learning strategies & 4 & 2 & 4 & 2.83 & 8.83 & 66 \\
\hline Technology-Acceptance & 4 & 2 & 2 & 2 & 8.83 & 71 \\
\hline University & 6 & 5 & 5 & 5 & 6.71 & 120 \\
\hline \multicolumn{7}{|c|}{ Interval 2014-2016 } \\
\hline Title & Works & H Index & G Index & Hg Index & $Q^{2}$ Index & Quotes \\
\hline College & 9 & 6 & 9 & 7.35 & 10.39 & 108 \\
\hline Intention & 22 & 11 & 19 & 14.46 & 17.23 & 376 \\
\hline University-Students & 21 & 8 & 12 & 9.8 & 12 & 160 \\
\hline Attitudes & 30 & 10 & 18 & 13.42 & 15.17 & 357 \\
\hline Facebook & 49 & 11 & 18 & 14.07 & 14.83 & 392 \\
\hline Technology & 41 & 8 & 14 & 10.58 & 12.65 & 240 \\
\hline B-learning & 45 & 7 & 10 & 8.37 & 8.37 & 147 \\
\hline Students & 23 & 8 & 12 & 9.8 & 12 & 154 \\
\hline Internet/Web-Based-Learning & 14 & 7 & 14 & 9.9 & 15.2 & 269 \\
\hline Online & 16 & 6 & 8 & 6.93 & 7.35 & 79 \\
\hline Academic-performance & 8 & 6 & 8 & 6.93 & 17.66 & 236 \\
\hline Mobile-learning & 9 & 2 & 5 & 3.16 & 6.63 & 36 \\
\hline Distance-education & 6 & 1 & 2 & 1.41 & 3.61 & 14 \\
\hline
\end{tabular}


Table 2. Cont.

\begin{tabular}{|c|c|c|c|c|c|c|}
\hline \multicolumn{7}{|c|}{ Interval 2017-2019 } \\
\hline Title & Works & H Index & G Index & Hg Index & $\mathrm{Q}^{2}$ Index & Quotes \\
\hline Technology-Acceptance-model & 34 & 5 & 8 & 6.32 & 7.42 & 74 \\
\hline University-Students & 21 & 6 & 8 & 6.93 & 6.93 & 80 \\
\hline Technology & 134 & 10 & 18 & 13.42 & 17.03 & 454 \\
\hline Self-efficacy & 32 & 6 & 7 & 6.48 & 7.35 & 83 \\
\hline Usage & 29 & 6 & 8 & 6.93 & 9.49 & 84 \\
\hline Education & 29 & 4 & 4 & 4 & 4.47 & 32 \\
\hline E-learning & 36 & 5 & 10 & 7.07 & 7.42 & 108 \\
\hline Internet-of-things & 19 & 4 & 8 & 5.66 & 8.25 & 80 \\
\hline Teachers & 11 & 2 & 6 & 3.46 & 8 & 46 \\
\hline Academic-performance & 10 & 3 & 6 & 4.24 & 5.2 & 37 \\
\hline System & 8 & 3 & 5 & 3.87 & 3.87 & 25 \\
\hline Mobile-devices & 9 & 2 & 3 & 2.45 & 4.24 & 15 \\
\hline Learning & 10 & 3 & 4 & 3.46 & 3.87 & 40 \\
\hline
\end{tabular}

The analysis of the five established diagrams shows a common pattern in the leading topics, such as the theme of university students, which is constantly repeated as a leading topic from the second period to the last. In all periods, the investigations are mainly focused on "self-efficacy", "attitudes" and "constructivism", although "Internet addiction" appears strongly in the last period.

In addition to the above, in the first period, the motor theme is "model", which guides the research on "web-based-training", "technology-acceptance" and "instruction". In this period, the focus is on technology acceptance and instruction models.

In the second period, in addition to "university students", we observe "medical-education", whose research is based on "computer-assisted-instruction", "curriculum" and "tool". In this period, research is more oriented towards the university students themselves, reflected in research on applications and curricular elements.

In the third period, in addition to "university students", we find "perceptions", whose studies are based on "knowledge", "user-acceptance", "learning-environment" and "medical-students". In this period, research also focuses on university students, but is more oriented towards acceptance, knowledge for use and learning environments.

In the fourth period, in addition to "university-students", "college", which deals with "film", "new literacies", "adolescence", "socio-cultural", "music" and "specific-media-hypertext"; "intention", which deals with "satisfaction", "self-efficacy", "adoption", "gender-differences", "model", "perspectives", "technology-acceptance-model" and "user acceptance" considered as the driving themes; "Facebook", which deals with "higher-education", "social-media", "social-networking", "Internet-use", "social-networks", "social-networking-sites", "twitter", and "university"; "attitudes", which deals with "acceptance", "computer-self-efficacy", "gender", "beliefs", "literacy", "perceptions", "perceived-usefulness" and "knowledge". During this period, the most interesting research areas were perhaps extended, in this case, to the university students and the technological resources closest to them.

In the last period, in addition to "university-students", the themes in "technology-acceptance-model", which deal with "perceived-ease", "Internet-banking", "computer-self-efficacy", "e-learning-systems", "information-technology", "behavioural-intention", "perceived-usefulness" and "used-acceptance" were also leading topics; "technology", which deals with "internet", "higher-education", "acceptance", "digital-natives", "environment", "experience", "model" and "students"; "self-efficacy", which deals with "continuance-intention", "adoption", "user-satisfaction", "attitudes", "beliefs", "intervention", "perceptions" and "performance"; "usage", which deals with "social-media", "information", "addiction", "college-students", "communication-technologies", "motivation", "preservice-teachers" and "university". In this last period, we must also bear in mind the themes "Internet-of-things", "systems" and "e-learning", given that, due to their location in the diagram, they are considered unknown themes, as they may be future 
driving forces, or may disappear from research. This period follows the line of the previous one, although, in addition to focusing on students, research focuses on learning self-efficacy and social networks (Figure 4).

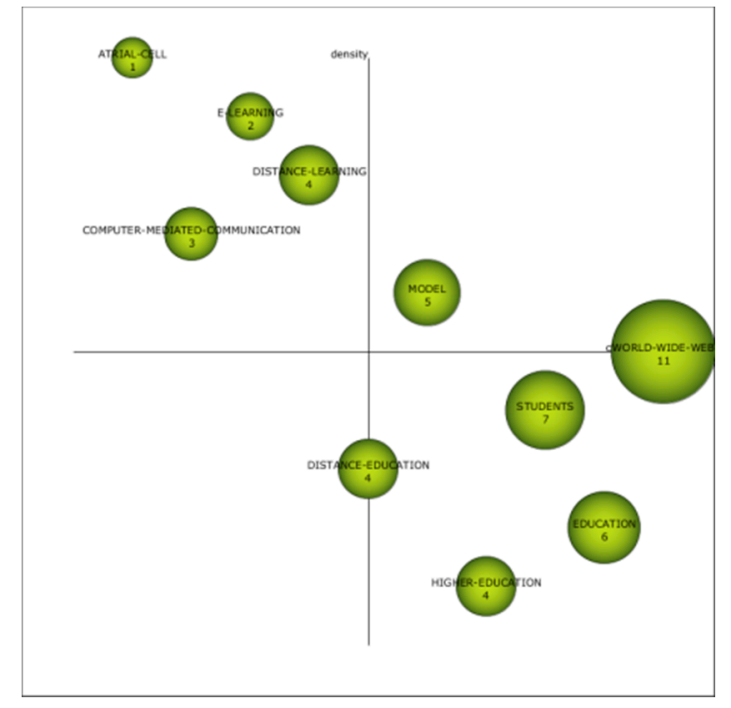

(a)

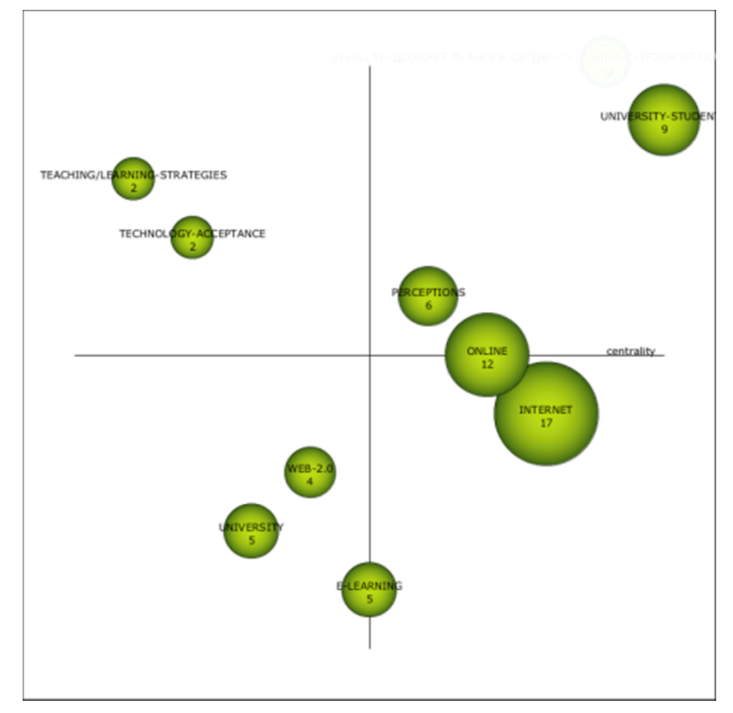

(c)

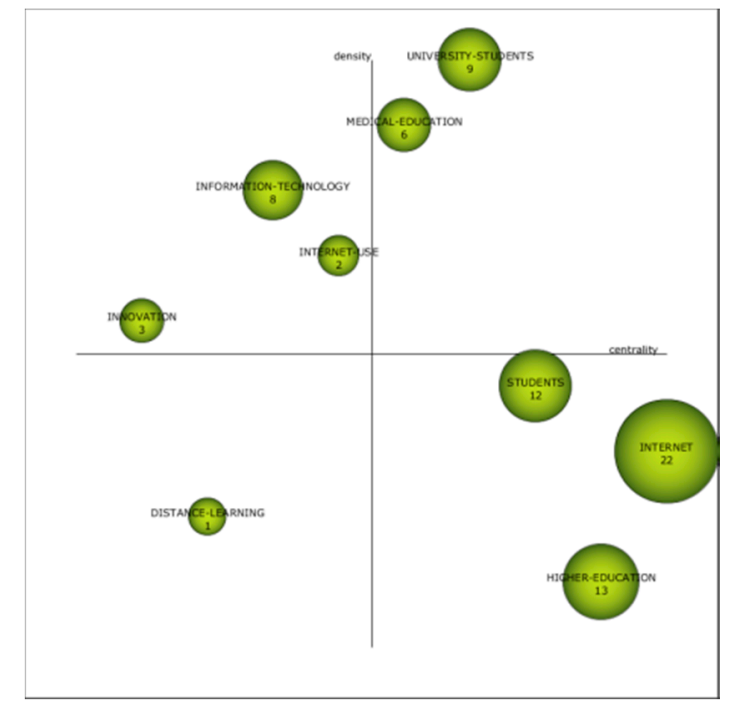

(b)

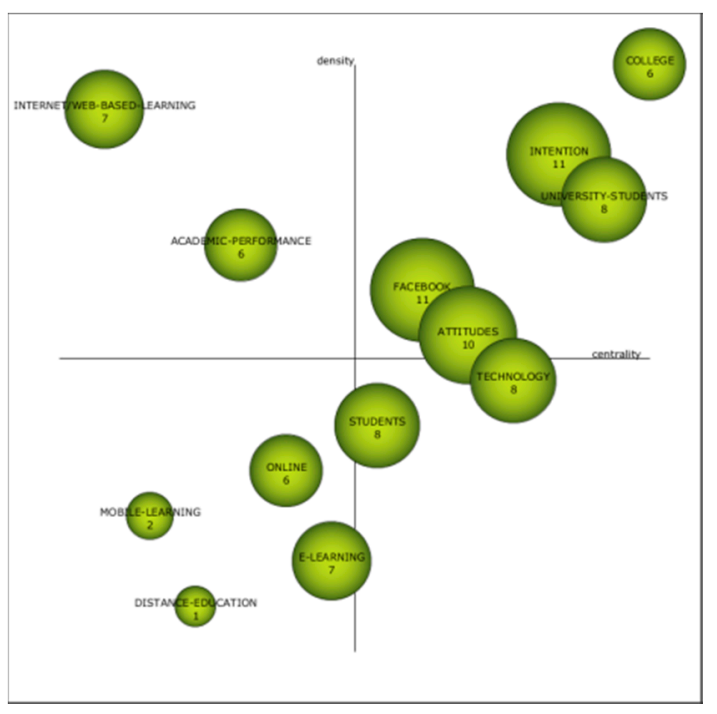

(d)

Figure 4. Cont. 


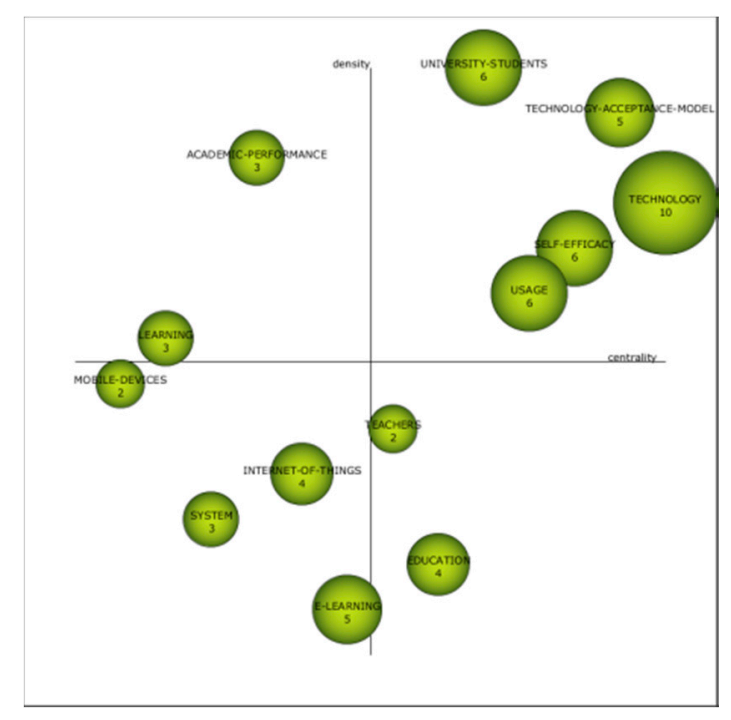

(e)

Figure 4. LINU's h-index strategic diagram. Note: (a) Interval 1993-2005; (b) Interval 2006-2010; (c) Interval 2011-2013; (d) Interval 2014-2016; (e) Interval 2017-2019.

\subsection{Thematic Evolution of Terms}

Bearing in mind the data shown in Figure 5, it can be established that a thematic gap exists, given that there is no theme that is repeated in all the established periods. Only "university-education" shows a line of thematic research, but only from the second period onwards; in addition, there are other thematic connections, although they are not constant over time, such as "Internet" in the second and third periods, or "technology" in the fourth and fifth periods. Most of the connections presented in the graph are thematic, since there are more continuous than discontinuous lines. The strongest connections are those that establish "education-Internet-Internet-technology" and "students-students-online-online-technology".

In both cases, the evolution is constant over time, although the main object of study varies. In addition, it can be seen that, in the first periods, the studies were mainly focused on training, students and educational innovation through the use of the Internet, while in the last periods, they were oriented towards the use of various technological means, distance learning and self-learning. 


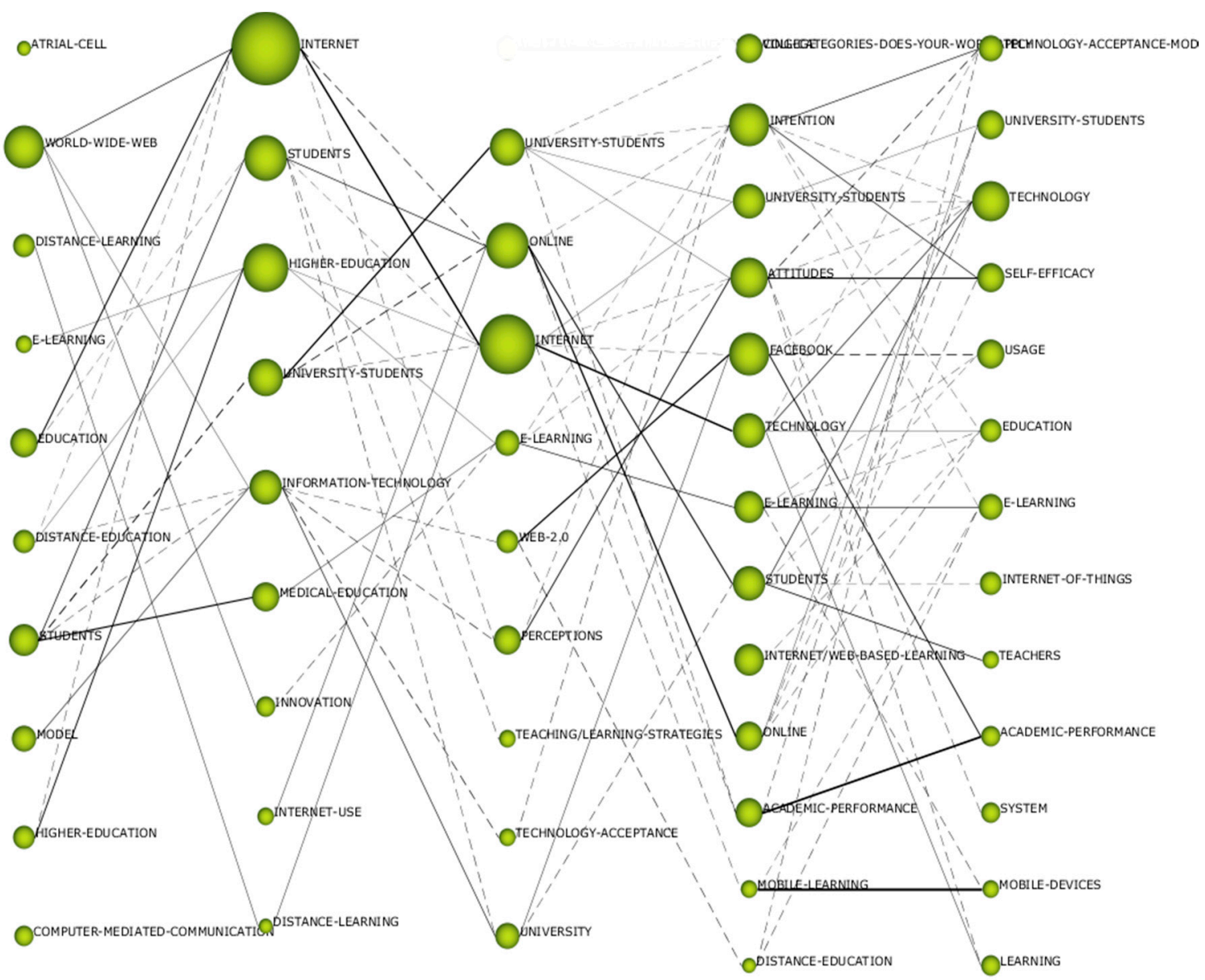

Figure 5. Thematic evolution by $\mathrm{h}$ index.

\subsection{Authors with the Highest Relevance Index}

As shown in Figure 6, the most prolific authors throughout the study period were Clausen, A., who works with Tampi, M., and Spanias, A.; Barbosa, F.P.M., who works with Valdez, M.T. and Ferreira, C.M.; Berankova, J., who works with Zerzanova, D., and Cechova, I.; and Markovic, C., who works with Vranes, A. and Mariokov, M.J. In addition, the authors Bogdanovic, Z., and Tsai, C.C., although they are not located in relevant positions in the diagram, are of interest to the scientific community, given their high h-indices. The authors Ozvoldova, M. and Dormido, S. should be kept in mind for the future of LINU, given that their location in the diagram places them as unknown authors, meaning that they may be relevant in the coming years or may tend towards disappearance. 


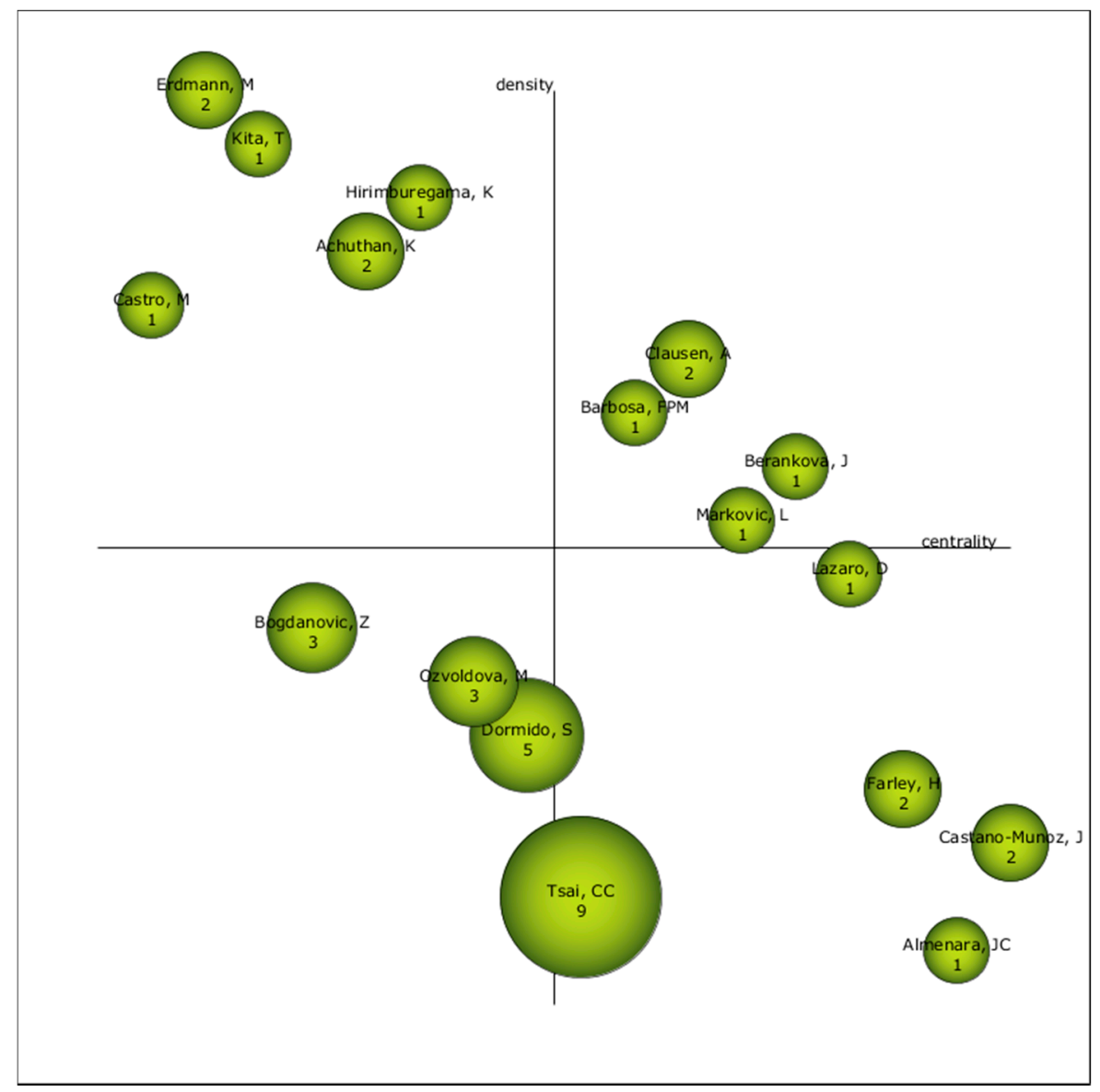

Figure 6. Strategic author diagram for the entire production of works.

\section{Discussion}

The new changes in information and communication technologies is a fact that is reflected in society. An example of this is the Internet, which is involved in most of our daily actions. The educational field is not unaware of this, especially in current times; due to the COVID-19 crisis, it has become the main medium for developing teaching and learning processes. This is being developed at all educational stages, especially in the university context (Baer 1998; Beyth-Marom et al. 2003; Datu et al. 2018; Djenic et al. 2011; Moorthy et al. 2019; Sun 2016; Taylor 1995).

Within this educational context, different techno-didactic tools offered by the Internet are effective for students' pedagogical development. These tools enable students to enhance their creativity and critical thinking (Allen et al. 2009; Khiste and Paithankar 2017; Koparal et al. 2019; Rathbone et al. 2020; Segura-Robles et al. 2019).

This research focuses on analyzing scientific works on the use of the Internet as an educational tool in the university context. From a descriptive perspective, a clearly defined profile of this type of study can be established. In this case, it can be observed that the total number of existing studies to date in the WoS database is 5118. These works start in 1993, and their production has seen a constant and ascending evolution from this date until 2017, with there being two important moments of decreases in production over the entire history of production: the dates between 2012 and 2014, and from 2017 to the present day. In addition, the language used by researchers to present their data is English, the most common category is education and educational research, and the type of document used for data presentation is research articles. The most prolific institution for these studies is the State University System of Florida. The author with the largest volume of production is Tsai, C.C., although the most significant authors are Clausen, A., Barbosa, F.P.M., Berankova, J., and Markovic, 
L. The journal with the largest scientific production on the subject is Procedia Social and Behavioral Science. The country with the highest production is the United States, and the most cited document is that of Kietzmann et al. (2011).

Regarding the analysis developed for co-words, it can be observed that the evolution is even throughout the established time periods, although changes in the lines of research are observed. This is due to the fact that the level of coincidence of words between periods decreases, which shows the establishment of new studies on the subject. The dates when this occurs are between 2006 and 2013 and between 2014 and 2019.

It can be established that there is no defined theme if the various bibliometric indicators are taken into account. This is because the topics with more bibliometric indicators vary between the established intervals. In this case, during the first three periods, the subject matter oscillates around the Internet and the world-wide-web, so it can be indicated that the line of research focuses on the use of the Internet-in this case, for the teaching processes of university students. However, in the fourth period, this changes, as research is more oriented towards technological resources-above all, focusing on resources of interest to students, as is the case with Facebook. Moreover, in this fourth period, intention and attitudes begin to be taken into account, which marks a new trend. This trend becomes more focused on people rather than on resources. In the last period, this line changes again, focusing on studies on technological resources. In this case, research is beginning to open up to the wide range of possibilities that currently exist at the level of educational software and apps.

The studies highlighted thus far refer to bibliometric values, but these topics are not the most relevant in each of the periods in our field of research. As can be seen, the most relevant themes do not vary greatly between the periods. The first period focuses mainly on teaching and learning models applied through the use of the Internet. However, from the second period to the present, the most relevant topics are oriented towards the students themselves, associating with their attitudes and technological resources.

Although these are the most relevant topics to date, the themes "Internet of Things", "systems" and "e-learning" should be taken into account, since they may be the new trends in this field of study.

In terms of the relationship of the evolution of the terms, a conceptual gap is observed; that is, there is no theme that is repeated in all the established times. This does not mean that there is not a solid line of research over time. In this case, there are two: "education-Internet-Internet-technology" and "students-students-online-online-technology". In other words, the trends focus on what has already been indicated above: on the one hand, technological resources, and students on the other.

\section{Conclusions}

As has been shown, it can be concluded that the LINU study theme has enjoyed considerable production, although in recent times, it has not been particularly significant for the scientific community. Throughout the research period, students-especially university students-have been the main focus of research; for example, in research works such as Vázquez-Cano et al. (2020). The research trends have evolved over time, focusing at first, on pedagogical innovation and moving towards technological resources-above all, those directed towards self-learning.

The prospect of this research is to offer researchers new trends in the near future regarding the most relevant and interesting topics for the scientific community, in addition to showing the aspects on which research has been based in recent times, so that researchers can have a base from which to start, develop and guide their studies.

There are several limitations of this research. The first is the establishment of the intervals; in this case, a question of equity, given that the researchers have always sought to maintain a similar number of documents in each of the intervals. Secondly, the parameters marked in this study have been established according to the researchers' own criteria, with the aim of presenting results in accordance with their size and relevance. As future lines of research, it is proposed to carry out this research in 
other specialized databases such as Scopus and, in this way, offer the scientific community another perspective on the state of the art according to this database.

Author Contributions: Conceptualization, A.S.-R., and M.-E.P.-G.; methodology, J.L.-B.; software, A.-J.M.-G.; formal analysis, J.L.-B., A.-J.M.-G., M.-E.P.-G., and A.S.-R.; investigation, J.L.-B., A.-J.M.-G., M.-E.P.-G., and A.S.-R.; data curation, A.-J.M.-G.; writing-original draft preparation, J.L.-B., A.-J.M.-G., M.-E.P.-G., and A.S.-R.; writing - review and editing, J.L.-B., A.-J.M.-G., M.-E.P.-G., and A.S.-R.; visualization, A.-J.M.-G., M.-E.P.-G., and A.S.-R.; supervision, J.L.-B. All authors have read and agreed to the published version of the manuscript.

Funding: This research received no external funding.

Conflicts of Interest: The authors declare no conflict of interest.

\section{References}

Allen, Liz, Ceri Jones, Kevin Dolby, David Lynn, and Mark Walport. 2009. Looking for landmarks: The role of expert review and bibliometric analysis in evaluating scientific publication outputs. PLoS ONE 4: 1-8. [CrossRef] [PubMed]

Alonso, Sergio, Francisco Javier Cabrerizo, Enrique Herrera-Viedma, and Francisco Herrera. 2010. hg-index: A new index to characterize the scientific output of researchers based on the h-and g-indices. Scientometrics 82 : 391-400. [CrossRef]

Baer, Walter S. 1998. Will the Internet Transform Higher Education? Santa Monica: Rand.

Beyth-Marom, Ruth, Eran Chajut, Sonia Roccas, and Lilach Sagiv. 2003. Internet-assisted versus traditional distance learning environments: Factors affecting students' preferences. Computers $\mathcal{E}$ Education 41: 65-76. [CrossRef]

Borko, Hilda, Jennie Whitcomb, and Daniel Liston. 2008. Wicked Problems and Other Thoughts on Issues of Technology and Teacher Learning. Journal of Teacher Education 60: 3-7. [CrossRef]

Carbonell, Xavier, Elena Guardiola, Marta Beranuy, and Ana Bellés. 2009. A bibliometric analysis of the scientific literature on Internet, video games, and cell phone addiction. Journal of The Medical Library Association: JMLA 97: 102-7. [CrossRef]

Cabrerizo, Francisco Javier, Sergio Alonso, Enrique Herrera-Viedma, and Francisco Herrera. 2010. q2-Index: Quantitative and qualitative evaluation based on the number and impact of papers in the Hirsch core. Journal of Informetrics 4: 23-28. [CrossRef]

Chen, Leida, Ravi Nath, and Zhenya Tang. 2020. Understanding the determinants of digital distraction: An automatic thinking behavior perspective. Computers in Human Behavior 104: 1-43. [CrossRef]

Cobo, Manuel Jesús, Antonio Gabriel López, Enrique Herrera, and Francisco Herrera. 2011. Science mapping software tools: Review, analysis, and cooperative study among tools. Journal of the American Society for Information Science and Technology 62: 1382-402. [CrossRef]

Cook, David A., Anthony J. Levinson, Sarah Garside, Denise M. Dupras, Patricia J. Erwin, and Victor M. Montori. 2008. Internet-based learning in the health professions-A meta-analysis. JAMA-Journal of the American Medical Association 300: 1181-96. [CrossRef]

Danet, Brenda, and Susan C. Herring. 2007. The Multilingual Internet: Language, Culture, and Communication Online. Oxford: Oxford University Press.

Datu, Jesús Alfonso, Weipeng Yang, Jana Patricia M. Valdez, and Samuel Kai Wah Chu. 2018. Is Facebook involvement associated with academic engagement among Filipino university students? A cross-sectional study. Computers and Education 125: 246-53. [CrossRef]

Djenic, Sanja, Radojka Krneta, and Jelena Mitic. 2011. Blended Learning of Programming in the Internet Age. IEEE Transactions on Education 54: 247-54. [CrossRef]

Feng, Shihui, Yip Kan Wong, Lai Yin Wong, and Liaquat Hossain. 2019. The Internet and Facebook Usage on Academic Distraction of College Students. Computers and Education 134: 41-49. [CrossRef]

Gogus, Aytac, and Yücel Saygin. 2019. Privacy perception and information technology utilization of high school students. Heliyon 5: 1-9. [CrossRef]

Golonka, Ewa, Anita R. Bowles, Victor M. Frank, Dorna L. Richardson, and Suzanne Freynik. 2012. Technologies for foreign language learning: A review of technology types and their effectiveness. Computer Assisted Language Learning 27: 70-105. [CrossRef] 
González-Hernando, Carolina, Lorena Valdivieso-León, and Verónica Velasco-González. 2020. Estudiantes universitarios descubren redes sociales y edublog como medio de aprendizaje. RIED. Revista Iberoamericana de Educación a Distancia 23: 223-39. [CrossRef]

Heradio, Ruben, Luis de la Torre, Daniel Galan, Francisco Javier Cabrerizo, Enrique Herrera-Viedma, and Sebastián Dormido. 2016. Virtual and remote labs in education: A bibliometric analysis. Computers and Education 98: 14-38. [CrossRef]

Hirsch, Jorge. 2005. An index to quantify an individual's scientific research output. Proceedings of the National Academy of Sciences of the United States of America 102: 16569-72. [CrossRef]

Kaminer, Noam, and Yale M. Braunstein. 1998. Bibliometric analysis of the impact of internet use on scholarly productivity. Journal of The American Society For Information Science 49: 720-30. [CrossRef]

Khiste, Gajanan, and Rajeev R. Paithankar. 2017. Analysis of Bibliometric Term in Scopus. International Journal of Library Science and Information Management 3: 81-88.

Kietzmann, Jan H., Kristopher Hermkens, Ian P. McCarthy, and y Bruno S. Silvestre. 2011. Social media? Get serious! Understanding the functional building blocks of social media. Business Horizons 54: 241-51. [CrossRef]

Koparal, Mahmut, Haluk Yener Ünsal, Hilal Alan, Fatih Üçkardeş, and Belgin Gülsün. 2019. WhatsApp messaging improves communication in an oral and maxillofacial surgery team. International Journal of Medical Informatics 132: 1-26. [CrossRef] [PubMed]

Kurt, Mehmet. 2010. Determination of in internet privacy behaviours of students. Procedia-Social and Behavioral Sciences 9: 1244-50. [CrossRef]

López, Jesús, Antonio-José Moreno-Guerrero, Juan Antonio López, and Santiago Pozo. 2019. Analysis of the Productive, Structural, and Dynamic Development of Augmented Reality in Higher Education Research on the Web of Science. Applied Science 9: 5306. [CrossRef]

López, Jesús, Adrian Segura-Robles, Antonio-José Moreno-Guerrero, and Elena Parra-González. 2020. Machine Learning and Big Data in the Impact Literature. A Bibliometric Review with Scientific Mapping in Web of Science. Symmetry 12: 495. [CrossRef]

López-Robles, José Ricardo, José Ramón Otegi-Olaso, Igone Porto, and Manuel Jesús Cobo. 2019. 30 years of intelligence models in management and business: A bibliometric review. International Journal of Information Management 48: 22-38. [CrossRef]

Mangold, W. Glynn, and David J. Faulds. 2009. Social media: The new hybrid element of the promotion mix. Business Horizons 52: 357-65. [CrossRef]

Martínez, Ma Ángeles, Manuel Jesús Cobo, Manuel Herrera, and Enrique Herrera. 2015. Analyzing the scientific evolution of social work using science mapping. Research on Social Work Practice 25: 257-77. [CrossRef]

Montero-Díaz, Julio, Manuel-Jesús Cobo, María Gutiérrez-Salcedo, Francisco Segado-Boj, and Enrique Herrera-Viedma. 2018. Mapeo científico de la Categoría «Comunicación» en WoS (1980-2013). Comunicar 26: 81-91. [CrossRef]

Moorthy, Krishna, Loh Chun T'ing, Khor Mei Wei, Pauline Tan Zi Mei, Chai Yan Yee, Kevin Jia Wern, and Yue Mei Xin. 2019. Is facebook useful for learning? A study in private universities in Malaysia. Computers and Education 130: 94-104. [CrossRef]

Moral-Muñoz, José Antonio, Enrique Herrera-Viedma, Antonio Santisteban-Espejo, and Manuel Jesús Cobo. 2020. Software tools for conducting bibliometric analysis in science: An up-to-date review. El Profesional de la Información 29: 1-20. [CrossRef]

Parra-González, María Elena, and Adrián Segura-Robles. 2019. Producción científica sobre gamificación en educación: un análisis cienciométrico. Revista de Educación 386: 109-31. [CrossRef]

Rana, Nripendra, Emma Slade, Sebastian Kitching, and Yogesh K. Dwivedi. 2019. The IT way of loafing in class: Extending the theory of planned behavior (TPB) to understand students' cyberslacking intentions. Computers in Human Behavior 101: 114-23. [CrossRef]

Rathbone, Adam, Ruth Norris, Paul Parker, Aidan Lindsley, Anna Robinson, Wasim Baqir, David Campbell, and Andy Husband. 2020. Exploring the use of WhatsApp in out-of-hours pharmacy services: A multi-site qualitative study. Research in Social and Administrative Pharmacy 16: 503-10. [CrossRef]

Rodríguez-García, Antonio Manuel, Jesús López, Miriam Agreda, and Antonio-José Moreno-Guerrero. 2019. Productive, Structural and Dynamic Study of the Concept of Sustainability in the Educational Field. Sustainability 11: 5613. [CrossRef] 
Rossing, Jonathan P., Willie M. Miller, Amanda K. Cecil, and Suzan E. Stamper. 2012. iLearning: The Future of Higher Education? Student Perceptions on Learning with Mobile Tablets. Journal of the Scholarship of Teaching and Learning 12: 1-26.

Sakhnini, Jacob, Hadis Karimipour, Ali Dehghantanha, Reza M. Parizi, and Guatman Srivastava. 2019. Security aspects of Internet of Things aided smart grids: A bibliometric survey. Internet of Things 22: 1-47. [CrossRef]

Segura-Robles, Adrián, María Angustias Sánchez-Ojeda, Miguel Ángel Gallardo-Vigil, and Inmaculada Alemany-Arrebola. 2019. Portable tutor: WhatsApp in nursing students $i$ internship and final degree Project processes. The European Proceedings of Social and Behavioural Sciences 1: 847-54. [CrossRef]

Sun, Jianrong. 2016. Convergence and Divergence in Blended Learning. In Blended Learning: Aligning Theory with Practices. Edited by S.K.S. Cheung En, L. Kwok, J. Shang, A. Wang and R. Kwan. Berlin/Heidelberg: Springer International Publishing, vol. 9757, pp. 292-301. [CrossRef]

Taylor, James C. 1995. Distance education technologies: The fourth generation. Australasian Journal of Educational Technology 11: 1-7. [CrossRef]

Vázquez-Cano, Esteban, Manuel León Urrutia, María Elena Parra-González, and Eloy López Meneses. 2020. Analysis of Interpersonal Competences in the Use of ICT in the Spanish University Context. Sustainability 12: 476. [CrossRef]

(C) 2020 by the authors. Licensee MDPI, Basel, Switzerland. This article is an open access article distributed under the terms and conditions of the Creative Commons Attribution (CC BY) license (http://creativecommons.org/licenses/by/4.0/). 